\title{
Antoine Fongaro, Les Lorettes, Baudelaire et quelques autres
}

\author{
Isabella Giovinazzo
}

\section{(e) OpenEdition}

1 Journals

\section{Edizione digitale}

URL: https://journals.openedition.org/studifrancesi/41021

DOI: 10.4000/studifrancesi.41021

ISSN: 2421-5856

\section{Editore}

Rosenberg \& Sellier

\section{Edizione cartacea}

Data di pubblicazione: 1 juillet 2004

Paginazione: 214

ISSN: 0039-2944

\section{Notizia bibliografica digitale}

Isabella Giovinazzo, «Antoine Fongaro, Les Lorettes, Baudelaire et quelques autres», Studi Francesi

[Online], 142 (XLVIII | I) | 2004, online dal 30 novembre 2015, consultato il 09 septembre 2021. URL: http://journals.openedition.org/studifrancesi/41021; DOI: https://doi.org/10.4000/studifrancesi. 41021

Questo documento è stato generato automaticamente il 9 septembre 2021.

\section{(c)}

Studi Francesi è distribuita con Licenza Creative Commons Attribuzione - Non commerciale - Non opere derivate 4.0 Internazionale. 


\title{
Antoine Fongaro, Les Lorettes, Baudelaire et quelques autres
}

\author{
Isabella Giovinazzo
}

\section{NOTIZIA}

ANTOINE FONGARO, Les Lorettes, Baudelaire et quelques autres, «Rivista di Letterature moderne e comparate» vol LVI. Fasc 2 (aprile - giugno 2003), pp. 183-206.

1 L'articolo è dedicato all'apparizione del termine lorette, che intorno agli anni ‘ 40 del XIX secolo si sostituisce progressivamente al tradizionale femme entretenue, e del quale si trovano numerose occorrenze nell'opera di Balzac, Gautier, Baudelaire e altri, prima di essere ancora rimpiazzato da demi-mondaine di Proust. In realtà attraverso lo studio di tale evoluzione terminologica, è possibile analizzare secondo l'A. i fenoneni di trasformazione sociale che caratterizzano la storia del Secondo Impero ed in particolare l'evoluzione economica che produce tra l'altro una nuova categoria di filles corrompues, i cui tratti caratteristici sono testimoniati anche dall'appellativo ad esse attribuito. 